\title{
States cooperate to check sea pollution
}

WITHIN the next few days, West Germany, the last of the seven signatories to the Helsinki Convention on the Protection of the Marine Environment of the Baltic Sea area, is expected to deposit its instrument of ratification with the Finnish government. Two months from that day, the convention will come legally into force - the only such agreement to date to cover every aspect of the protection of the marine environment. The delay, caused by federal structure, has not, however, prevented the contracting countries from already embarking on a major programme of work on Baltic ecology.

The Baltic water is of exceptionally low salinity. This results in an ecology of low diversity, which is extremely vulnerable to environmental change. Accordingly, no sooner was the convention drafted in 1974, than a working party, the Interim Commission, was set up to carry out a number of preliminary tasks, including getting to grips with the scientific problems.

Foremost among such tasks is the permanent monitoring of the Baltic for pollution. The convention defines potential pollutants as hazardous (DDT and the PCB and PCT compounds), noxious (heavy metals, radioactive substances, etc) and oil. Seven of these have been selected as immediate priority areas (till 1983), with responsibility for research assigned on the lead country principle: Denmark for PCB and PCT's, West Germany for lead, East Germany for copper and zinc, Poland for DDT, USSR for mercury, Finland for oil, and Sweden for cadmium.

Basic research is not directly the concern of the Commission, although it does serve as a coordinator of the results of the environmental programmes of the individual countries. (Its cumulative bibliography of relevant publications in the Baltic countries since 1970 will be published shortly and there is a proposal to set up an international Baltic library). The main task of the Commission is to work out a coordinated monitoring programme, permitting the direct comparison of results.

A five-year pilot programme was initiated in March 1979. Sampling is to be carried out both at coastal stations and at specified locations at sea. Tests include both the physical monitoring of sea water parameters, and also biological specimens - notably herring, cod, Macoma baltica, eider duck, arctic tern and red breasted merganser. To ensure comparability, especially with the biological specimens, a massive file of methodological guidelines, covering all aspects from age and maturity of the specimens selected to test procedures and presentation of results, has been compiled. This is not yet in its final form, but, according to Dr Ilppo Kaugas, the scientific expert of the Interim Commission, only a very few minor comments and amendments have been proposed.

Intercalibration workshops form an important part of this monitoring programme. To date, these have included a chemical intercalibration workshop at Kiel in 1975 and one on biological calibration methods in 1979. A meeting on biomass, financed by the Commission and organised by Polish marine biologists, will be held in Gdynia in May of this year. In general, Dr Kaugas told Nature, the methodology for secondary production is still somewhat vague, and much work may be expected in this field in the future.

The most urgent problem; however, is that of oil spills and ship safety. In the narrow confines of the Baltic, even a close in-shore spill can affect the coasts and waters of other countries. The February 1979 spill of Ventspils harbour (Latvian SSR) ended up on the shores of Sweden and Finland. One recent idea, put forward by a Swedish team, is that all oil cargoes should be "tagged" by the addition of a mixture of metal particles. In the case of a spill, the relative composition of the tagging mixture could be determined by microscopic and mass-spectrographic methods, and this composition, which would be specific to each ship, would, when the convention comes into force, be considered as legal evidence, comparable to a fingerprint.

A large-scale international experiment on tagging methods was mounted last autumn, investigating such factors as the effect of climatic and meteorological factors on tagged oil. According to $\mathrm{Dr}$ Kaugas, the experiments were, in principle, a success, and similar methods "or possibly better" may well be introduced in the future.

Much attention is also being paid to general problems of ship-safety, including the logistics of long-distance pilotage of incoming tankers from the Kattegat to their home ports. One major problem facing the Commission is, however, that of ships sailing under the flags of countries not covered by the convention. "Everything depends in this case on the goodwill of the masters sailing under foreign flags", Dr Kaugas explained. For, although it was at the UN Conference on the Human Environment in Stockholm in 1972 that the Finnish delegation first raised the necessity of international action on the Baltic, and although it is proposed that, when the Permanent Commission is in operation, it will supply data from its monitoring programme to the UN Regional Seas Project, the Helsinki Convention is, essentially, a private agreement between the seven countries bordering the Baltic. The high standard of its monitoring work, and of its anti-pollution proposals (which, once it is signed, will be binding on the participating countries), may well, however, become a blueprint for other future international conventions on marine environments that would cover the whole range of sea-going nations. Vera Rich

Women in Helsinki washing carpets in the waters of the port. The seven Baltic states are working to ensure the sea stays clean enough for this spring-cleaning tradition to persist

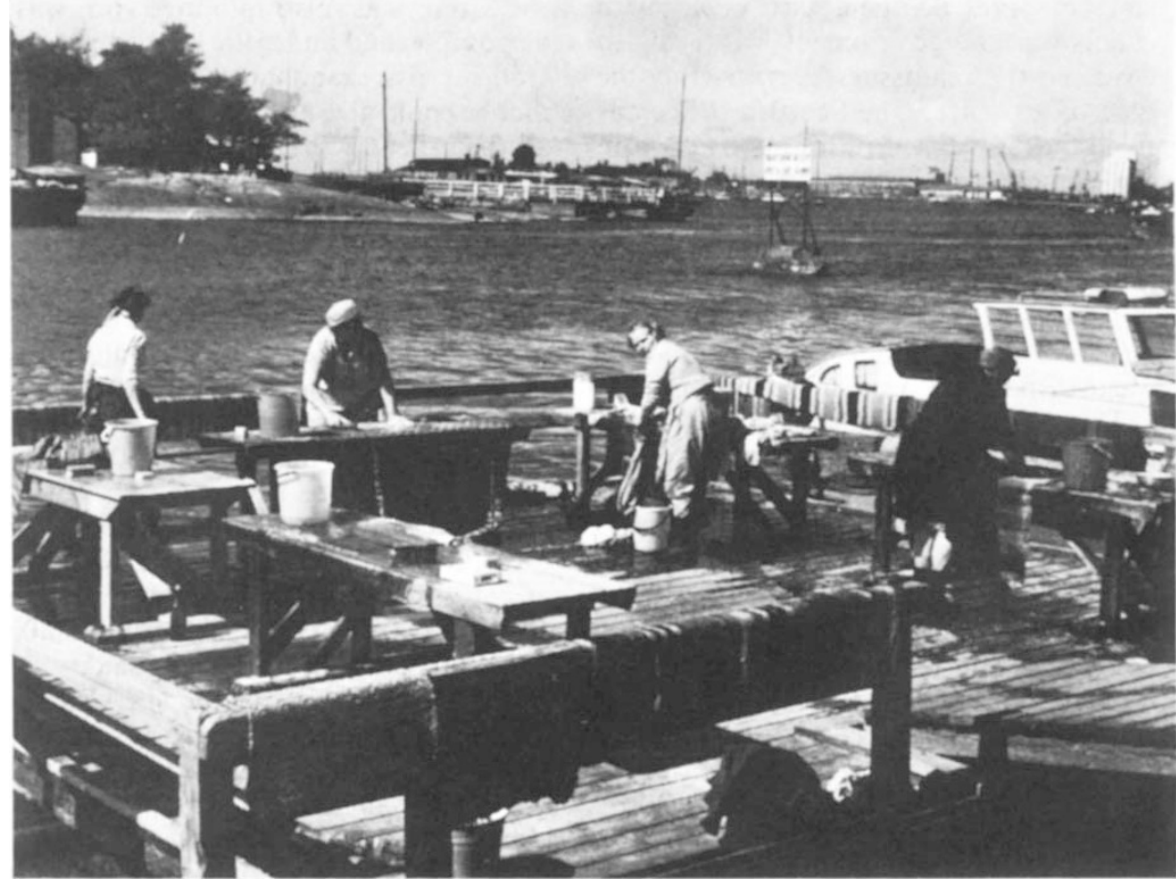

